\title{
Salt-free electrolysis of water facilitated by hydrogen gas in thin layer cell
}

\author{
This article was published in the following Dove Press journal: \\ Reports in Electrochemistry \\ 18 July 2013 \\ Number of times this article has been viewed
}

\section{Chunyan Li \\ Koichi Jeremiah Aoki \\ Jingyuan Chen \\ Toyohiko Nishiumi}

Department of Applied Physics, University of Fukui, Fukui, Japan
Correspondence: Koichi Jeremiah Aoki Department of Applied Physics, University of Fukui, 3-9-I Bunkyo, Fukui, $910-0017$ Japan

Tel $+8 \mid 776278665$

Fax +8I 776278750

Email kaoki@u-fukui.ac.jp
Abstract: Electrolysis of water without salt in a thin layer cell requires a voltage of more than $1.3 \mathrm{~V}$. This voltage is found to be reduced to $0.4 \mathrm{~V}$ when hydrogen gas is dissolved in electrolyzed water. The decrease in the overvoltage can be used for the salt-free electrolysis of pure water. Thin layer electrolysis under steady state is often caused by redox cycling. The redox cycling model relevant to the reaction between $\mathrm{H}_{2}$ and $\mathrm{H}^{+}$is theoretically analyzed here in a two-electrode cell. The validity and limitation are discussed on the basis of the experimental voltammograms of a solution containing $\mathrm{H}_{2}$ and $\mathrm{H}^{+}$. When a solution contains $\mathrm{H}_{2}$ without deliberately adding $\mathrm{H}^{+}$, hydrogen gas would not be expected at the cathode due to the small amount of $\mathrm{H}^{+}$. Consequently redox cycling might be blocked. However, experimental voltammograms, without the addition of $\mathrm{H}^{+}$, exhibited the steady state limiting current by redox cycling. The current was regarded as dissociation kinetics of water. The redox cycling in this case was theoretically analyzed to partially explain the experimental results. The oxidation of hydrogen gas at the anode facilitates the dissociation kinetics to produce redox cycling.

Keywords: redox cycling, hydrogen gas, dissociation kinetics of water, electrolysis of pure water in thin layer cell, CE mechanism under the steady state

\section{Introduction}

Electrochemical microreactors have the advantages of facilitating ionic transport due to local electric fields, interaction of products at an anode and a cathode, and unexpected reactions with salts. ${ }^{1,2}$ A number of uses have been reported and reviewed. ${ }^{3}$ For example, they include the possibility of electrode reactions at low concentration of supporting electrolyte, ${ }^{4-7}$ electrochemical treatments of water without supporting electrolytes in a flow-through cell, ${ }^{8}$ mass transport of electrochemical products to a counter electrode, ${ }^{9}$ and local voltage control by segmented electrodes. ${ }^{10} \mathrm{~A}$ disadvantage of microreactors is poor control of currents by electrode potential because of limitation of space for a reference electrode, although specific cell geometry has made it possible to obtain cyclic voltammograms. ${ }^{11}$

A thin layer cell acts as a microreactor, in that it can cause electrolysis without supporting electrolyte, which is demonstrated by electrolysis of pure water. ${ }^{12}$ Once a very small amount of water is electrolyzed into $\mathrm{H}^{+}$and $\mathrm{OH}^{-}$, these ions enhance electric conduction in the cell. Change in conductivity during electrolysis has been addressed by studies in the field of microelectrode voltammetry. ${ }^{13-24}$ Further complication in a thin layer cell involves reaction coupling or redox cycling, ${ }^{25}$ in which products at the anode reach the cathode where they react. Redox cycling ought to enhance reaction rates, as seen in reactions of interdigitated electrodes. ${ }^{26-28}$ 
One of the key features of redox cycling is not only the interaction of the oxidized and the reduced species but also the mass transport between two electrodes. ${ }^{29-35} \mathrm{~A}$ required condition of redox cycling is the presence of equal amounts of the reduced and the oxidized species. If the concentration of the oxidized species is lower than that of the reduced one, two possibilities can be predicted. One is that the current will be controlled by the minor species, with the major species making no contribution to the redox cycling. The other possibility is that the current is not necessarily controlled by the minor species because the minor species is produced electrochemically from the major one. Which possibility really occurs may depend on other conditions such as mass transport in and out of the thin layer cell, chemical complications, and the level of electric neutrality. We examine here which possibility occurs in water electrolysis by adding hydrogen ion to pure water as a major species. Mass transport, including the dissociation kinetics, is considered theoretically here and compared with the experimental results.

\section{Materials and methods}

The disk electrodes, $1.6 \mathrm{~mm}$ in diameter, coated with polyether ether ketone in cylindrical form, were commercially available (BAS, Tokyo, Japan). The two electrodes were confronted each other so that the space between the two formed a thin layer cell. One of the two electrodes was fixed horizontally, whereas the other was moved in the direction of the cylindrical body axis by means of a micrometer gauge on an optical positioner. The axis of the cylindrical body was fitted to the axis of the other rod. The electrodes and the space were coated using a polyethylene vessel, which was a part of a bellows pipette. ${ }^{12}$ Pure water was inserted into the vessel through a hole at the top of the vessel by means of a syringe.

Water was prepared with an ultrapure water system, CPW100 (Advantec, Tokyo, Japan), and was deaerated with nitrogen gas or hydrogen gas. The resistivity of the water before electrochemical measurements was $18 \mathrm{M} \Omega \cdot \mathrm{cm}$, as determined by using a conductivity meter equipped with the pure water generator. The resistivity was measured after each of the following steps: when water was transferred into the glass vessel, when water was left standing exposed to air for a short time, and when it was injected by use of a plastic injector. The resistivity values by a conductometer, DS-71 (Horiba, Kyoto, Japan), decreased to $1.7 \mathrm{M} \Omega \cdot \mathrm{cm}$ after 30 minutes exposure to air.

Hydrogen gas was bubbled for 15 minutes into water of the cell, which was set in hydrogen atmosphere. The distance between the two electrodes was read by the micrometer gauge from the contacting point of the two surfaces nearest each other. Voltage was applied to the two electrodes with a potentiostat (CompactStat; Ivium Technologies, Eindhoven, The Netherlands). The reference and the counter electrode as for conventional voltammetry were $\mathrm{Ag} / \mathrm{AgCl}(3 \mathrm{M} \mathrm{KCl})$ and a platinum wire, respectively.

Salt-free voltammograms for redox cycling were obtained by facing two platinum rods without insulator. These electrodes exhibited reproducible voltammograms because there is no boundary between the platinum electrode and the insulator which causes floating large capacitive currents. We confirmed that voltammograms at the insulated disks were close to those at the rod electrodes.

\section{Results}

\section{Redox cycling between $\mathrm{H}_{2}$ and $\mathrm{H}^{+}$ in thin layer cell}

In order to understand the ideal behavior of redox cycling, we performed thin layer voltammetry of the reaction, $\mathrm{H}_{2} \leftrightarrow 2 \mathrm{H}^{+}+2 \mathrm{e}^{-}$, in the presence of $\mathrm{H}_{2}$ and $\mathrm{H}^{+}$. Figure 1 shows voltammograms in $1 \mathrm{M} \mathrm{KCl}+\mathrm{H}_{2}+\mathrm{HCl}$ aqueous solution for several concentrations of $\mathrm{HCl}$ in the thin layer cell when hydrogen gas was saturated in the solution, where $\Delta E$ is the applied voltage. Voltammograms were confirmed to be point-symmetric with respect to $I=0$ and $\Delta E=0$, as can be predicted from the symmetric voltammograms of two-electrode electrolysis. They were almost under the steady state for $v \leq 10 \mathrm{mV} \mathrm{s}^{-1}$. Since the current at the forward scan was smaller than that at the backward one for

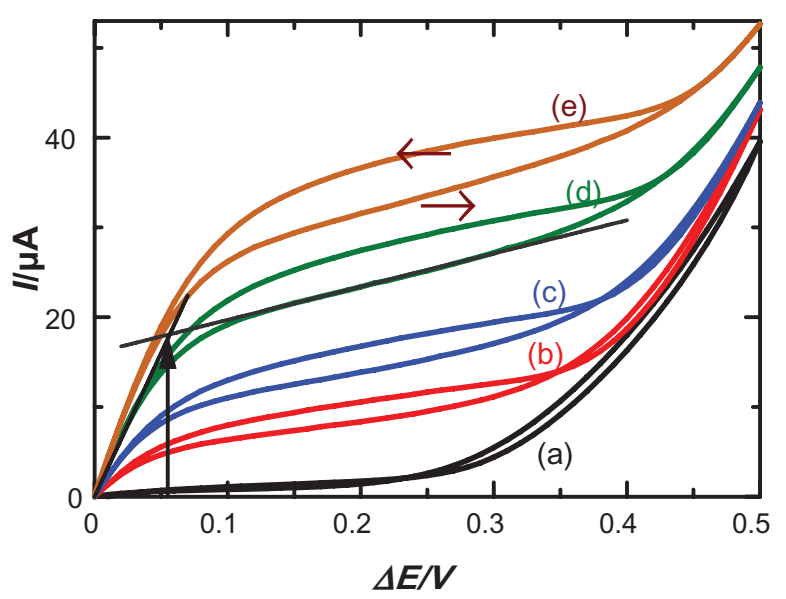

Figure I Voltammograms of I $\mathrm{M} \mathrm{KCl}+$ saturated $\mathrm{H}_{2}+x \mathrm{mM} \mathrm{HCl}$ at $v=30 \mathrm{mV} \mathrm{s}^{-1}$ in the thin layer cell for $w=50 \mu \mathrm{m}$, where $x=$ (a) 0 , (b) 0.05 , (c) 0.1 , (d) 0.2 and (e) 0.3 . Notes: The arrows indicate the direction of the potential scans. The drawing process of determining the limiting current is shown in (d). 
$v>30 \mathrm{mV} \mathrm{s}^{-1}$ (Figure 1), the hysteresis was not caused by the capacitive current, but may have been caused by the time required for reaching the steady-state for the redox cycling. The electrolysis time for reaching the limiting current was approximately 3 seconds for the $0.1 \mathrm{~V}$ potential domain at $v=30 \mathrm{mV} \mathrm{s}^{-1}$ in Figure 1. The thickness of the diffusion layer was $50 \mu \mathrm{m}$, which was comparable to the interdistances of the electrodes. Therefore, the hysteresis should be contained in the voltammograms.

Conventional voltammograms in $1 \mathrm{M} \mathrm{KCl}+\mathrm{H}_{2}$ aqueous solution were made to understand the reactions in the thin layer cell. Figure 2 shows the voltammogram in the potential domain covering water decomposition. Peak (a) is the oxidation of $\mathrm{H}_{2}$, of which current was proportional to $v^{1 / 2}$. Waves (b) and (c) are ascribed to the oxidation and the reduction of water, respectively. The potential difference of the two waves is $2.0 \mathrm{~V}$. In contrast, the potential difference of the redox cycling in Figure 1 (a) was approximately $0.4 \mathrm{~V}$. Consequently, $1.6 \mathrm{~V}$ was gained by use of the thin layer cell.

Figure 3 shows variation of the limiting current, $I_{\text {lim }}$, of the voltammograms in Figure 1 with the concentration of $\mathrm{HCl}$. The current is approximately proportional to the $\mathrm{H}^{+}$concentration $\left[\mathrm{H}^{+}\right]$when $\left[\mathrm{H}^{+}\right]<0.2 \mathrm{mM}$. A possible reason for the deviation from the proportionality for $\left[\mathrm{H}^{+}\right]>0.3 \mathrm{mM}$ is blocking of the product $\left(\mathrm{H}_{2}\right)$ at the cathode by adsorption. ${ }^{36-39}$ The other possibility is ambiguity of the determination of the limiting currents, as will be discussed later. It is predicted that the current is inversely proportional to $w$ owing to the control by diffusion in the finite domain $w .{ }^{29}$ Figure 4 shows dependence of the limiting current on $1 / w$, as shown in circles. The plot at narrow distances between the electrodes deviated from the proportional line. Since the electrode surface was polished before every voltammetric run using a polishing buff, it was deformed to a rounded surface, ${ }^{40}$ as shown in the inset of Figure 4. Values of $w$ were read from the moving distance from the closest contact point of the two electrodes by a micrometer gauge. Therefore the average distance should be larger than $w$. We measured $w_{2}$ with the microscope as shown in the inset, and obtained the curvature, from which we evaluated the effective interelectrode distance, $w_{1}=w+10 \mu \mathrm{m}$. The plot of the limiting current with $1 / w_{1}$ (triangles) fell on the proportional line.

We derive here expressions for current-voltage curves of the redox cycling reaction, $2 \mathrm{H}^{+}+2 \mathrm{e}^{-} \leftrightarrow \mathrm{H}_{2}$, when mass transport of both species is controlled only by diffusion in the $x$-direction of the cell under the steady state. It is

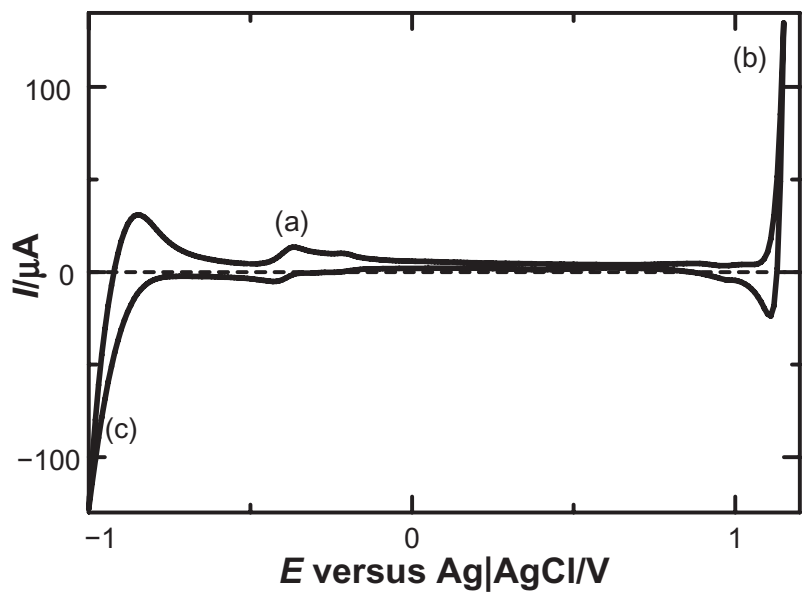

Figure 2 Voltammogram of $\mathrm{I} \mathrm{M} \mathrm{KCl}+$ saturated $\mathrm{H}_{2}$ solution at the platinum disk electrode $1.6 \mathrm{~mm}$ in diameter for $v=30 \mathrm{mV} \mathrm{s}^{-1}$.

Notes: (a) oxidation of $\mathrm{H}_{2}$, (b) oxidation of water, and (c) reduction of water.

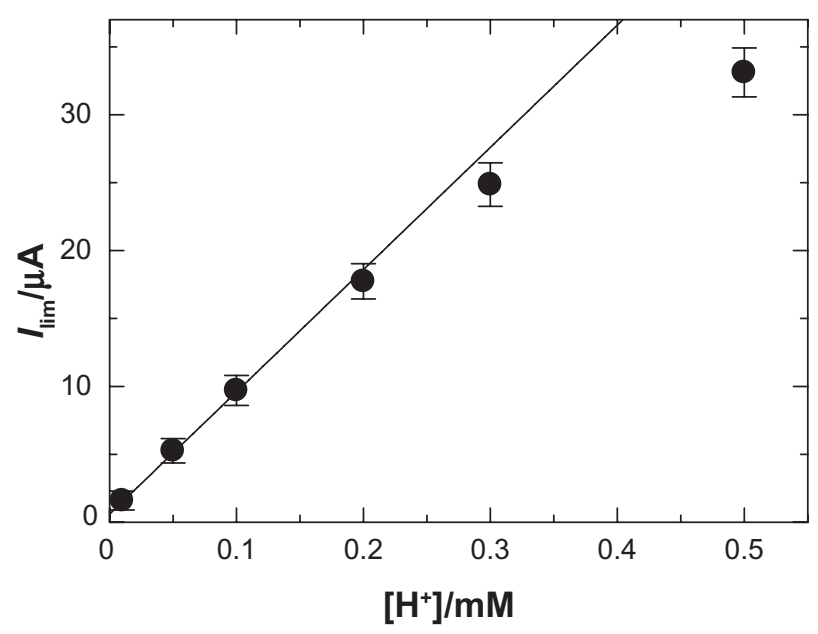

Figure 3 Dependence of the limiting current of the voltammograms in Figure I on concentrations of $\mathrm{HCl}$.

Abbreviations: $\mathrm{H}+$, concentration of hydrogen ion; $l_{\text {lim, }}$, the limiting current.

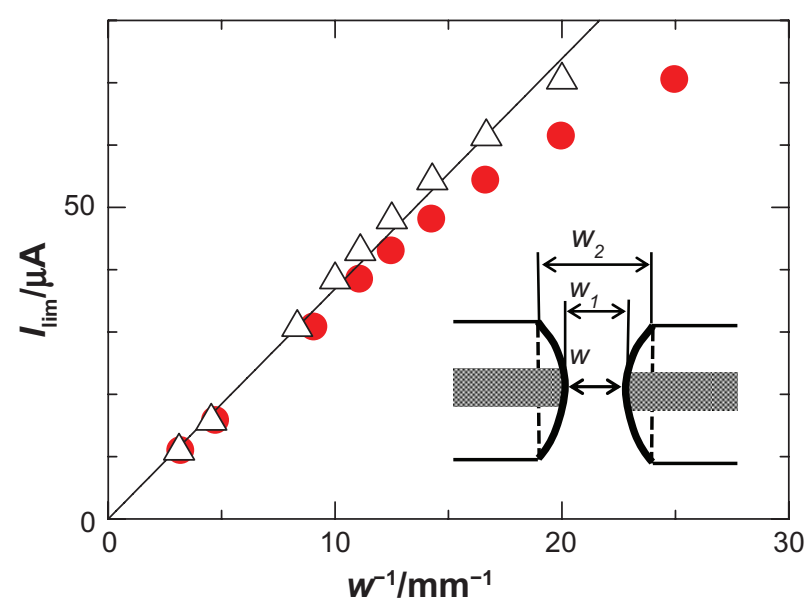

Figure 4 Variation of the limiting currents with $I / w$ (circles) and $I / w_{1}$ (triangles) under the conditions of Figure I, where $w_{1}=w+10 \mu \mathrm{m}$.

Note: The inset is the illustration of the rounded electrode surfaces.

Abbreviations: $I_{\text {lim }}$, the limiting current; $w$, distance between two facing electrodes. 
assumed that the reaction occurs in accordance with the Nernst response at the anode and the cathode. We located the anode and the cathode at $x=0$ and $w$, respectively, as illustrated in Figure 5. The detailed derivation is described in the Supplementary materials. The dimensionless currentvoltage curves represented by Equation S8 vary with the parameter $b$. Figure 6 shows variation of the dimensionless current-voltage curves for several values of $c_{+}{ }^{*} / c_{\mathrm{H} 2} *$.

Large values of $(2 F / R T) \Delta E$ in Equation S8 correspond to the domain of the limiting current, which is equivalent to infinitesimally small values of $(2-f)(b-f)$. When $f$ increases from zero, Equation S8 tends to infinity at a smaller value of either 2 or $b$. Therefore, we have the limiting current, $f=2$ for $b>2$ and $f=b$ for $b<2$. Since Equation S9 becomes $b=1.9 c_{+} * / c_{\mathrm{H} 2} *$ for $D_{+}=8.7 \times 10^{-5} \mathrm{~cm}^{2} \mathrm{~s}^{-1}$ and $D_{\mathrm{H} 2}=4.6 \times 10^{-5} \mathrm{~cm}^{2} \mathrm{~s}^{-1}$, 11 the condition $b>2$ corresponds approximately to $c_{+}{ }^{*}>c_{\mathrm{H} 2}{ }^{*}$, for which $f=2$. Consequently the limiting current is expressed by

$$
\begin{aligned}
& j_{\lim }=4 F c_{\mathrm{H} 2}^{*} D_{\mathrm{H} 2} / w \text { for } b>2 \text { or } c_{+}^{*}>c_{\mathrm{H} 2}^{*} \\
& j_{\lim }=2 F c_{+}^{*} D_{+} / w \text { for } b<2 \text { or } c_{+}^{*}<c_{\mathrm{H} 2}^{*}
\end{aligned}
$$

The "4" involved in Equation 1 arises from both the twoelectron oxidation and the accumulation of $\mathrm{H}_{2}$ on the cathode by the reduction of $\mathrm{H}^{+}$at the cathode so that $\left(c_{\mathrm{H} 2}\right)_{x=0}=2 c_{\mathrm{H} 2} *$, as can be illustrated in Figure 5 .

Although Equation 1 mentions that the limiting current for $c_{+}{ }^{*}<c_{\mathrm{H} 2}{ }^{*}$ is proportional to $c_{+}{ }^{*}$, the experimental results in Figure 3 showed the lower deviation from the proportional

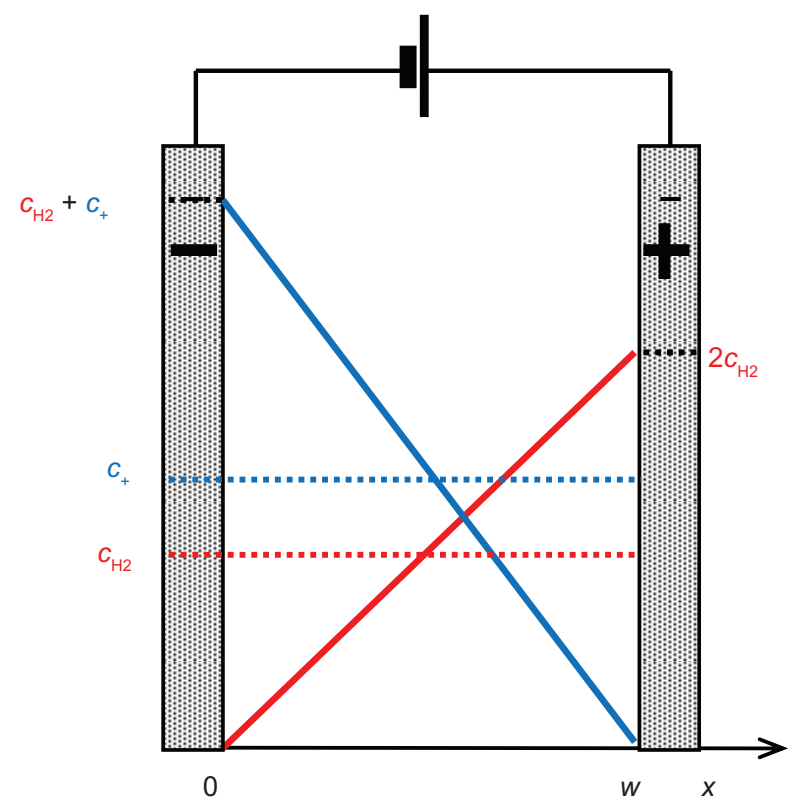

Figure 5 Model of thin layer cell and predicted concentration profiles. Abbreviations: $x$, distance from the anode toward the cathode; $\mathrm{C}_{\mathrm{H} 2}$, concentration of hydrogen gas; $C_{+}$, concentration of hydrogen ion.

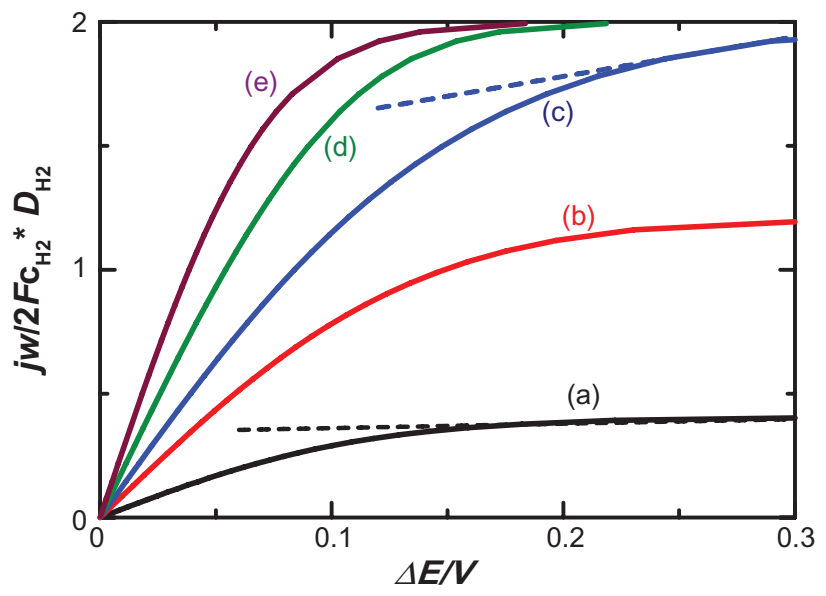

Figure 6 Current-voltage curves calculated from Equation S8 at $c_{+}^{*} / c_{\mathrm{H} 2} *=($ a) 0.2 , (b) 0.6, (c) 1.0, (d) 2.0 and (e) 5.0 .

Notes: The dashed lines are tangents of curves at $\Delta \mathrm{E}=0.25 \mathrm{~V}$.

Abbreviations: $\Delta \mathrm{E}$, the applied voltage; $j w / 2 \mathrm{Fc}_{\mathrm{H} 2}{ }^{2} \mathrm{D}_{\mathrm{H} 2}$, dimensionless current

line for $c_{+}^{*}>0.3 \mathrm{mM}$. When $c_{+}{ }^{*}$ is close to $c_{\mathrm{H} 2} *$ in Figure 6, (a) $\rightarrow$ (c), a plateau of the limiting current becomes vague. In fact, the slopes (dashed lines (a) and (c) in Figure 6) of the limiting currents increase with an increase in $c_{+}^{*}$. Experimental values of the limiting currents may be underestimated. The slope of the proportional line in Figure 3 is $90 \mathrm{~mA} \mathrm{M}^{-1}$, whereas the theoretical value calculated from Equation $\mathrm{S} 8$ is $110 \mathrm{~mA} \mathrm{M}^{-1}$. If $w$ is corrected to $w+10 \mu \mathrm{m}$ for the roundness of the electrode surface, the theoretical slope is $93 \mathrm{~mA} \mathrm{M}^{-1}$, which is close to the experimental value.

Redox cycling might occur also for $\mathrm{O}_{2}+2 \mathrm{H}_{2} \mathrm{O}+4 \mathrm{e}^{-} \leftrightarrow$ $4 \mathrm{OH}^{-}$. We attempted to perform voltammetry for dioxygen and sodium hydroxide instead of $\mathrm{H}_{2}$ and $\mathrm{HCl}$. The voltammograms in the thin layer cell did not show any limiting current, but were similar to those of pure water. ${ }^{12}$ The disappearance of limiting current may be ascribed to such a large overpotential difference between the cathodic and the anodic reaction of dioxygen that it may overlap with the wave of water decomposition.

\section{Redox cycling in the absence of $\mathrm{H}^{+}$}

Figure 7 shows voltammograms of water including only hydrogen gas for various values of $w$, demonstrating appearance of the limiting current plateau for $\Delta E>0.4 \mathrm{~V}$. Since the solution has no ions, the solution resistance should be very large. Nevertheless, the limiting current was observed. This is an advantage of the thin layer cell voltammetry. Equation 1 mentions that limiting current by the redox cycling in solution without deliberate addition of hydrogen ion should be $93 \mathrm{~mA} \mathrm{M}^{-1} \times 10^{-7} \mathrm{M}=9 \mathrm{nA}$ at $\mathrm{pH} 7$. However, the observed voltammetric shape and current values are extremely different from the theoretical ones. Specifically, 


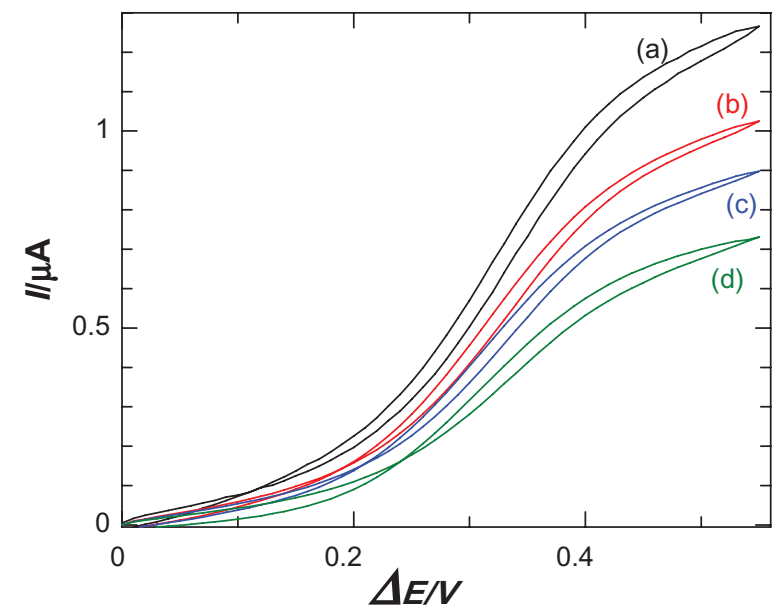

Figure $\mathbf{7}$ Voltammograms of water including hydrogen gas without deliberately adding $\mathrm{H}^{+}$for $w=$ (a) 30 , (b) 40 , (c) 50 and (d) $70 \mu \mathrm{m}$ at $v=30 \mathrm{mV} \mathrm{s}^{-1}$.

Abbreviations: $\Delta \mathrm{E}$ the applied voltage; $l$, the current.

features of the voltammograms are: (1) Steady-state voltammograms; (2) A sigmoidal wave rising up at $0.2 \mathrm{~V}$; (3) Values of the limiting current being 100 times larger than the theoretical value; (4) The limiting currents which increase with a decrease in $w$. Features 1 and 4 suggest the presence of some kind of redox cycling, whereas features 2 and 3 cannot be simply explained in terms of the redox cycling of $\mathrm{H}_{2} \leftrightarrow 2 \mathrm{H}^{+}+2 \mathrm{e}^{-}$. The appearance of the inactive potential domain (from $0 \mathrm{~V}$ to $0.2 \mathrm{~V}$ ) suggests participation in the kinetics other than diffusion. A possible kinetics is a supply of $\mathrm{H}^{+}$from the dissociation of water rather than from the solution bulk, because the dissociation is the only source of $\mathrm{H}^{+}$in the present experiment.

We considered the problem of mass transport including the dissociation when the redox cycling by $2 \mathrm{H}^{+}+2 \mathrm{e}^{-} \rightarrow \mathrm{H}_{2}$ occurs in the thin layer cell; the redox cycling is composed of the dissociation through the $\mathrm{CE}$ reaction, $\mathrm{H}_{2} \mathrm{O} \leftrightarrow \mathrm{H}^{+}+\mathrm{OH}^{-}$ and $2 \mathrm{H}^{+}+2 \mathrm{e}^{-} \rightarrow \mathrm{H}_{2}$. It is assumed that the diffusion coefficients of $\mathrm{H}^{+}$and $\mathrm{OH}^{-}$have a common value, $D$. Feature 3 implies that the consumed amount of hydrogen gas is much smaller than the bulk concentration of hydrogen gas. Therefore $c_{\mathrm{H} 2}$ can be regarded as the bulk value. It is $\left[\mathrm{H}^{+}\right]$ and $\left[\mathrm{OH}^{-}\right]$that vary in the thin layer cell. Expressions for $\left[\mathrm{H}^{+}\right]$and $\left[\mathrm{OH}^{-}\right]$will be derived in Supplementary materials, and they will yield current-voltage curves.

Dimensionless current $(g)$ versus voltage curves can be calculated from Equation S24 for some values of $\lambda$, and are plotted in Figure 8. Sigmoidal curves were obtained and are similar to the experimental ones (Figure 7). However, the potential shift of the experimental curves is larger than the theoretical ones. A possible reason is ohmic drop of water. The resistivity of water 30 minutes after use was $1.7 \mathrm{M} \Omega \cdot \mathrm{cm}$, which yields

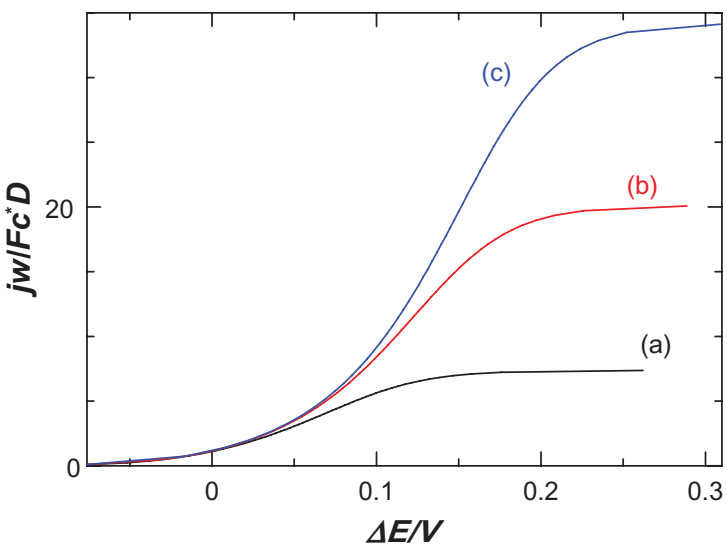

Figure 8 Theoretical voltammograms calculated from Equation S24 for $\lambda=(a) 10$, (b) 45 and (c) 100 .

Notes: Conditions of (b) corresponds, for example, to $w=0.05 \mathrm{~mm}$ at $k_{r}=1.4 \times$ $10^{11} \mathrm{M}^{-1} \mathrm{~s}^{-1}$ and $D=5 \times 10^{-5} \mathrm{~cm}^{2} \mathrm{~s}^{-1}$

Abbreviations: $\Delta \mathrm{E}$, the applied voltage; $j w / F c * D$, the dimensionless current.

$0.14 \mathrm{~V}$ potential shift at $0.5 \mu \mathrm{A}$. This value explains the potential difference. We have assumed that values of the diffusion coefficients of $\mathrm{H}^{+}$and $\mathrm{OH}^{-}$were common, although the ratio of the former to the latter is approximately 1.7. It provides 1.3 times difference in $\lambda$ through Equation S20. This ratio is negligibly small in the variations in Figure 8.

The condition of taking the limiting current is $2 \lambda=g^{3 / 2}$ from Equation S24. Then the limiting current is expressed by

$$
j_{\lim }=F c^{*} D(2 \lambda)^{2 / 3} / w=F c^{*} D w^{-1 / 3}\left(2 k_{r} c^{*} / D\right)^{1 / 3}
$$

Equation 2 indicates that the limiting current has the $-1 / 3$ power of $w$. However, the experimental results show -0.8 power of $w$, as exhibited in Figure 9, probably because Equation 2 has been derived on the assumption that the reaction

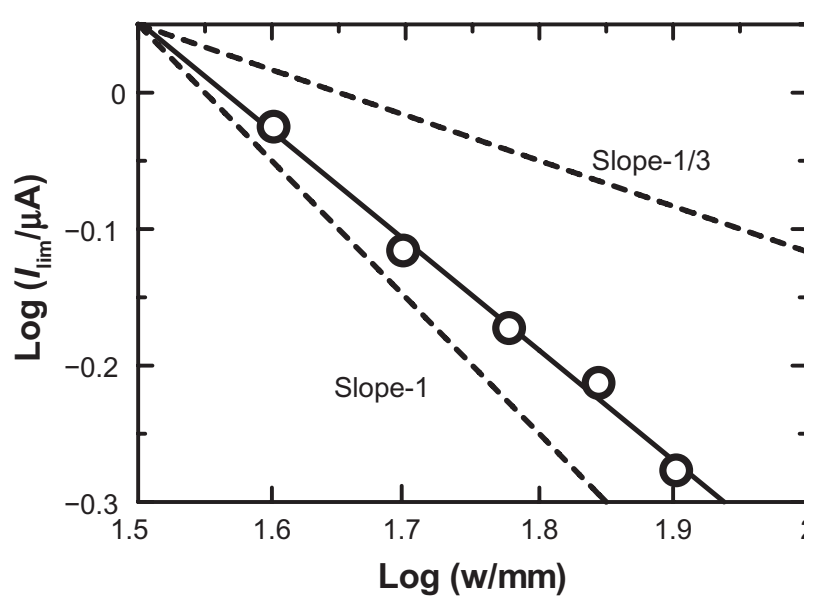

Figure 9 Plot of the limiting currents in Figure 6 against $w$ in the logarithmic scale where $w$ was added as $10 \mu \mathrm{m}$ to the geometrical interelectrode distance.

Abbreviations: $w$, distance between two closest electrodes; $l_{\text {lim }}$, the limiting current. 
layer was much thinner than $w$. Therefore, the experimental results fell between $w^{-1 / 3}$ and $w^{-1}$ (Figure 9). The current value calculated from Equation 2 for $D=8.6 \times 10^{-5} \mathrm{~cm}^{2} \mathrm{~s}^{-1}$, $c^{*}=10^{-7} \mathrm{M}, k_{\mathrm{r}}=1.4 \times 10^{11} \mathrm{M}^{-1} \mathrm{~s}^{-1}$ and $w=0.05 \mathrm{~mm}$ is $0.08 \mu \mathrm{A}$. This is ten times smaller than the experimental value. The small value is ascribed to the assumption of the thin reaction layer. The value of $(2 \lambda)^{2 / 3}$ in Equation 2 is 14, which is a gain of $\mathrm{H}^{+}$supplied from the dissociation.

We can understand the four features of the absence of hydrogen ion through the theoretical voltammograms. The steady-state (1) of the voltammograms is ascribed to the redox cycling of $\mathrm{H}_{2}$ and $\mathrm{H}^{+}$, where hydrogen ion is supplied from the dissociation of water. The sigmoidal form (2) is attributed to the potential shift by $\ln (\lambda)$ in Equation S24. Non-zero values of the slope of the current at $\Delta E=0$ in Figure 1 are caused by the reversible redox reaction when both $\mathrm{H}_{2}$ and $\mathrm{H}^{+}$are present, whereas the zero values in Figure 7 are obtained when either species is absent in solution. The latter is in accord with the experimental results in the absence of hydrogen ion. One hundred times smaller values of the limiting current than the redox cycling currents (3) can be explained in terms of the dissociation kinetics. The inconsistency (Figure 9) between the theory and the experiment (4) regarding the dependence of the limiting currents on $w$ arises from the oversimplification of the theory by neglecting diffusion in the kinetic dissociation layer.

\section{Discussion}

The redox cycling of $\mathrm{H}_{2} \leftrightarrow 2 \mathrm{H}^{+}+2 \mathrm{e}^{-}$in the thin layer cell including both $\mathrm{H}_{2}$ and $\mathrm{H}^{+}$provides the steady state voltammograms approximately according to the theoretical prediction. The steady state is established for $v<10 \mathrm{mV} \mathrm{s}^{-1}$ and $w<0.05 \mathrm{~mm}$ to yield the limiting currents. The limiting current is proportional to the concentration of hydrogen ion in the low concentration domain, partly because of adsorption of produced hydrogen and partly because of the vague waveform. The limiting current is inversely proportional to $w$ if the curvature effect $(10 \mu \mathrm{m})$ of the electrode surface is taken into account. Attention must be paid to accuracy as the thickness of the thin layer cells may be less than $10 \mu \mathrm{m}$.

Even when hydrogen ion is not added deliberately to the solution, the redox cycling occurs. The voltammogram has a sigmoidal shape with a positive potential shift. The limiting current is much smaller than that of the normal redox cycling. These variations can be explained in terms of the control by the dissociation kinetics of water. The approximation of the reaction layer includes oversimplification for the dissociation kinetics. As a result, observed dependence of the limiting current on $w$ is closer to the dependence for the simple redox cycling than the theory.

\section{Acknowledgment}

This work was financially supported by Grants-in-Aid for Scientific Research (Grant 25420920) from the Ministry of Education in Japan.

\section{Disclosure}

The authors report no conflicts of interest in this work.

\section{References}

1. Loewe H, Ehrfeld W. State-of-the-art in microreaction technology: concepts, manufacturing and applications. Electrochim Acta. 1999; 44(21-22):3679-3689.

2. Watts P, Haswell SJ, Pombo-Villar E. Electrochemical effects related to synthesis in micro reactors operating under electrokinetic flow. Chem Eng J. 2004; 101(1-3):237-240.

3. Bouzek K, Jiricny V, Kodym R, Kristal J, Bystron T. Microstructured reactor for electroorganic synthesis. Electrochim Acta. 2010; 55(27):8172-8181.

4. Scialdone O, Galia A, Guarisco C, Mantia SL. Abatement of 1,1,2,2tetrachloroethane in water by reduction at silver cathode and oxidation at boron doped diamond anode in micro reactors. Chem Eng J. 2012; 189-190:229-236.

5. Paddon CA, Pritchard GJ, Thiemann T, Marken F. Paired electrosynthesis: micro-flow cell processes with and without added electrolyte. Electrochem Commun. 2002;4(10):825-831.

6. Attour A, Rode S, Ziogas A, Matlosz M, Lapicque F. A thin-gap cell for selective oxidation of 4-methylanisole to 4-methoxy-benzaldehydedimethylacetal. J Appl Electrochem. 2008;38(3):339-347.

7. Attour A, Rode S, Lapicque F, Ziogas A, Matlosz M. Thin-Gap SinglePass High-Conversion Reactor for Organic Electrosynthesis II. Application to the Anodic Methoxylation of 4-Methoxytoluene. J Electrochem Soc. 2008;155(12):E201-E206.

8. Scialdone O, Guarisco C, Galia A, et al. Anodic abatement of organic pollutants in water in micro reactors. J Electroanal Chem. 2010; 638(2):293-296.

9. Belmont C, Girault HH. Coplanar interdigitated band electrodes for electrosynthesis, Part 3: Epoxidation of propylene. Electrochim Acta. 1995;40(15):2505-2510.

10. Rode S, Altmeyer S, Matlosz M. Segmented thin-gap flow cells for process intensification in electrosynthesis. J Appl Electrochem. 2004;34(7):671-680.

11. Sakairi M, Yamada M, Kikuchi T, Takahashi H. Development of three-electrode type micro-electrochemical reactor on anodized aluminum with photon rupture and electrochemistry. Electrochim Acta. 2007;52(21):6268-6274.

12. Aoki KJ, Li C, Chen J, Nishiumi T. Electrolysis of pure water in a thin layer cell. J Electroanal Chem. 2013; 695:24-29.

13. Baker DR, Verbrugge MW, Newman J. A transformation for the treatment of diffusion and migration. Application to stationary disk and hemisphere electrodes. J Electroanal Chem. 1991;314(1-2):23-44.

14. Oldham KB. Theory of steady-state voltammetry without supporting electrolyte. J Electroanal Chem. 1992;337(1-2):91-126.

15. Amatore A, Fosset B, Bartelt J, Deakin MR, Wightman RM. Electrochemical kinetics at microelectrodes: Part V. Migrational effects on steady or quasi-steady-state voltammograms. J Electroanal Chem. 1988;256(2):255-268.

16. Oldham KB, Cardwell TJ, Santos JH, Bond AM. Effect of ion pairing on steady-state voltammetric limiting currents at microelectrodes Part I. Theoretical principles. J Electroanal Chem. 1997;430(1-2):25-37. 
17. Bond AM, Fleischmann M, Robinson MJ. Electrochemistry in organic solvents without supporting electrolyte using platinum microelectrodes. J Electroanal Chem. 1984;168(1-2):299-312.

18. Montenegro MI, Queiros MA, Daschbach JL, editors. Microelectrodes: Theory and Applications. Dordrecht, The Netherlands: Kluwer; 1991.

19. Lee C, Anson FC. Inhibition of the electroreduction of $\mathrm{Fe}(\mathrm{CN}) 63$ at microelectrodes in the absence of supporting electrolyte: Mediation of the inhibited reduction by methyl viologen. J Electroanal Chem. 1992;323(1-2):381-389.

20. Aoki K. Theory of ultramicroelectrodes. Electroanalysis. 1993;5(8): 627-639.

21. Myland JC, Oldham KB. General theory of steady-state voltammetry. J Electroanal Chem. 1993;347(1-2):49-91.

22. Ciszkowska M, Stojek Z. Voltammetry in solutions of low ionic strength. Electrochemical and analytical aspects. J Electroanal Chem. 1999;466(2):129-143.

23. Jaworski A, Stojek Z, Osteryoung JG. Oxidation of mercury microelectrodes in complexing media in the presence and absence of supporting electrolyte: Formation of thiocyanate complexes. J Electroanal Chem 2003;558:141-153.

24. Aoki K, Tokida A. Resistance of solution without supporting electrolyte under the reduction of HCl. Electrochim Acta. 2000;45(21): 3483-3488.

25. Paddon CA, Atobe M, Fuchigami T, et al. Towards paired and coupled electrode reactions for clean organic microreactor electrosyntheses. J Appl Electrochem. 2006;36(6):617-634.

26. Aoki K, Morita M, Niwa O, Tabei H. Quantitative analysis of reversible diffusion-controlled currents of redox soluble species at interdigitated array electrodes under steady-state conditions. J Electroanal Chem. 1988;256(2):269-282.

27. Niwa O, Morita M, Tabei H. Electrochemical behavior of reversible redox species at interdigitated array electrodes with different geometries: consideration of redox cycling and collection efficiency. Anal Chem. 1990;62(5):447-452.

28. Dam VAT, Olthuis W, van den Berg A. Redox cycling with facing interdigitated array electrodes as a method for selective detection of redox species. Analyst. 2007;132:365-370.

29. Daruhazi L, Tokuda K, Farsang G. Cyclic voltammetry for reversible redox-electrode reactions in thin-layer cells with closely separated working and auxiliary electrodes of the same size. J Electroanal Chem. 1989;264(1-2):77-89.
30. Zhu F, Yan J, Lu M, Zhou Y, Yang Y, Mao B. A strategy for selective detection based on interferent depleting and redox cycling using the plane-recessed microdisk array electrodes. Electrochim Acta. 2011; 56(24):8101-8107.

31. Vandaveer WR, Woodward DJ, Fritsch I. Redox cycling measurements of a model compound and dopamine in ultrasmall volumes with a self-contained microcavity device. Electrochim Acta. 2003; 48(20-22):3341-3348.

32. Wolfrum B, Zevenbergen M, Lemay S. Nanofluidic Redox Cycling Amplification for the Selective Detection of Catechol. Anal Chem. 2008;80(4):972-977.

33. Lemay SG, Kang S, Mathwig K, Singh PS. Single-molecule electrochemistry: present status and outlook. Acc Chem Res. 2013; 46(2):369-377.

34. Spilker B, Randhahn J, Grabow H, Beikirch H, Jeroschewski P. New electrochemical sensor for the detection of hydrogen sulfide and other redox active species. J Electroanal Chem. 2008; 612(1):121-130.

35. van Megen MJJ, Odijk M, Wiedemair J, Olthuis W, van den Berg A. Differential cyclic voltammetry for selective and amplified detection. J Electroanal Chem. 2012:681:6-10.

36. Elving PJ, Spritzer MS. Polarographic reduction of hydrogen ion in non-aqueous solvents. Talanta. 1965;12(12):1243-1258.

37. Lipkowski J, Ross PN, editors. Chapter 7, IR spectroscopy of molecules at solid-solution interface. Adsorption of Molecules at Metal Electrodes VCH, New York; 1992.

38. Nanbu N, Kitamura F, Ohsaka T, Tokuda K. Adsorption of atomic hydrogen on a polycrystalline Pt electrode surface studied by FT-IRAS: the influence of adsorbed carbon monoxide on the spectral feature. J Electroanal Chem. 2000;485(2):128-134.

39. Clavilier J, Feliu J.M, Fernandez-Vega A, Aldaz A. Electrochemical behaviour of the $\mathrm{Pt}$ (111)-As system in acidic medium: adsorbed hydrogen and hydrogen reaction. J Electroanal Chem. 1990;294(1-2): 193-208.

40. Aoki K, Xian C. Relaxation Time of Memorial Diffusion by Chronoamperometry at a Twin-electrode. J Phys Chem. C. 2007;111(42) : 15433-15439.

41. Aoki K, Toda H, Yamamoto J, Chen J, Nishiumi T.Is hydrogen gas in water present as bubbles or hydrated form?. J Electroanal Chem. 2012;668:83-89. 


\section{Supplementary materials}

Expressions for the limiting current are derived in these supplementary materials. Since a solution of the steady state diffusion equation in the domain $0<x<w$ is a linear variation of $x$, concentrations of $\left[\mathrm{H}^{+}\right]=c_{+}$and $\left[\mathrm{H}_{2}\right]=c_{\mathrm{H} 2}$ are expressed by

$$
c_{+}=p+s x, \quad c_{\mathrm{H} 2}=q-r x
$$

where $p, q, r$, and $s$ are positive constants. Fluxes at $x=0$ by both species are given by

$$
D_{+}\left(\mathrm{d} c_{+} / \mathrm{d} x\right)_{x=0}=-2 D_{\mathrm{H} 2}\left(\mathrm{~d} c_{\mathrm{H} 2} / \mathrm{d} x\right)_{x=0}=j / F
$$

or we have

$$
D_{+} s=2 D_{\mathrm{H} 2} r=j / F
$$

where $D_{+}$and $D_{\mathrm{H} 2}$ are diffusion coefficients of $\mathrm{H}^{+}$and $\mathrm{H}_{2}$, respectively. Letting the electrode potentials at the cathode and the anode be $E_{\mathrm{C}}$ and $E_{\mathrm{A}}$, respectively, we can express the Nernst equations at both electrodes as

$$
\begin{aligned}
& E_{\mathrm{C}}-E^{\circ}=\frac{R T}{2 F} \ln \frac{\left(c_{+}\right)_{x=0}^{2}}{\left(c_{\mathrm{H} 2}\right)_{x=0}}=\frac{R T}{2 F} \ln \frac{p^{2}}{q} \\
& E_{\mathrm{A}}-E^{\circ}=\frac{R T}{2 F} \ln \frac{(p+s w)^{2}}{q-r w}
\end{aligned}
$$

The voltage controlled by a two-electrode potentiostat is $\Delta E=E_{\mathrm{A}}-E_{\mathrm{C}}$. Then we have

$$
\Delta E=\frac{R T}{2 F} \ln \frac{(p+s w)^{2}}{q-r w} \frac{q}{p^{2}}
$$

Since the amount of the species does not change by electrolysis within the cell, it should keep the loaded amount, regardless of concentration profiles. By letting loaded concentrations be $c_{\mathrm{H} 2}{ }^{*}$ and $c_{+}{ }^{*}$, the trapezoidal profiles yield

$$
(2 p+s w) w / 2=c_{+}^{*} w, \quad(2 q-r w) w / 2=c_{\mathrm{H} 2}^{*} w
$$

Extracting $p$ and $q$ and replacing $s$ and $r$ by $j / F$ in Equation S2, we obtain

$$
\begin{aligned}
& p=c_{+}^{*}-s w / 2=c_{+}^{*}-j w / 2 F D_{+} \\
& q=c_{\mathrm{H} 2}^{*}+r w / 2=c_{\mathrm{H} 2}^{*}+j w / 4 F D_{\mathrm{H} 2}
\end{aligned}
$$

Eliminating $p, q, s$, and $r$ from Equation $\mathrm{S} 4$ by use of Equations $\mathrm{S} 2$ and $\mathrm{S} 5$ yields

$$
\frac{2 F}{R T} \Delta E=\ln \frac{c_{\mathrm{H} 2}^{*}+j w / 4 F D_{\mathrm{H} 2}}{c_{\mathrm{H} 2}^{*}-j w / 4 F D_{\mathrm{H} 2}}\left(\frac{c_{+}^{*}+j w / 2 F D_{+}}{c_{+}^{*}-j w / 2 F D_{+}}\right)^{2}
$$

We define the dimensionless current density as

$$
f=j w / 2 F c_{\mathrm{H} 2}^{*} D_{\mathrm{H} 2}
$$

Then Equation S6 becomes

$$
\exp \left(\frac{2 F}{R T} \Delta E\right)=\frac{2+f}{2-f}\left(\frac{b+f}{b-f}\right)^{2}
$$

where

$$
b=\frac{c_{+}^{*} D_{+}}{c_{\mathrm{H} 2}^{*} D_{\mathrm{H} 2}}
$$

The kinetics-involved diffusion equations for $\left[\mathrm{H}^{+}\right]=c_{+}$ and $\left[\mathrm{OH}^{-}\right]=c-$ at a planar electrode under the steady state is given by

$$
\begin{aligned}
& \frac{\mathrm{d}^{2} c_{+}}{\mathrm{d} x^{2}}=-\left(k_{\mathrm{d}}\left[\mathrm{H}_{2} \mathrm{O}\right]-k_{\mathrm{r}} c_{+} c_{-}\right) / D \\
& \frac{\mathrm{d}^{2} c_{-}}{\mathrm{d} x^{2}}=-\left(k_{\mathrm{d}}\left[\mathrm{H}_{2} \mathrm{O}\right]-k_{\mathrm{r}} c_{+} c_{-}\right) / D
\end{aligned}
$$

where $k_{\mathrm{d}}$ is the dissociation rate constant and $k_{\mathrm{r}}$ is the recombination rate constant. These rate constants can be related with the equilibrium constant, $K$, through

$K=\frac{k_{\mathrm{d}}}{k_{\mathrm{r}}}=\frac{c_{+}^{*} c_{-}^{*}}{\left[\mathrm{H}_{2} \mathrm{O}\right]}, K\left[\mathrm{H}_{2} \mathrm{O}\right]=c_{+}^{*} c_{-}^{*}=K_{w}=10^{-14} \mathrm{M}^{2}$

The boundary conditions for the concentrations are given by the Nernst equations under the assumption of the invariance of $c_{\mathrm{H} 2}$

$E_{\mathrm{C}}-E^{\circ}=\frac{R T}{2 F} \ln \frac{\left(c_{+}\right)_{x=0}^{2}}{c_{\mathrm{H} 2}^{*}}, E_{\mathrm{A}}-E^{\circ}=\frac{R T}{2 F} \ln \frac{\left(c_{+}\right)_{x=w}^{2}}{c_{\mathrm{H} 2}^{*}}$

Hydrogen ion participates in the electrode reaction, whereas hydronium ion does not. Then the fluxes at the electrodes define the current density:

$$
\begin{gathered}
\frac{j}{F}=D\left(\frac{\mathrm{d} c_{+}}{\mathrm{d} x}\right)_{x=0}=D\left(\frac{\mathrm{d} c_{+}}{\mathrm{d} x}\right)_{x=w}, \\
\left(\frac{\mathrm{d} c_{-}}{\mathrm{d} x}\right)_{x=0}=0, \quad\left(\frac{\mathrm{d} c_{-}}{\mathrm{d} x}\right)_{x=w}=0
\end{gathered}
$$


Furthermore, electric neutrality holds within the cell:

$$
\int_{0}^{w} c_{+} \mathrm{d} x=\int_{0}^{w} c_{-} \mathrm{d} x
$$

Taking the subtraction of Equation S10 from S11 yields $\mathrm{d}^{2}\left(c_{+}-c_{-}\right) / \mathrm{d} x^{2}=0$ or $c_{+}-c_{-}=k_{1}+k_{2} x$ for constants $k_{1}$ and $k_{2}$. Applying conditions S14 and Equation S15, we have

$$
c_{+}-c_{-}=-\frac{j w}{2 F D}+\frac{j}{F D} x
$$

It is assumed that the reaction rate is so fast that the reaction zone is restricted to domain near the electrode surface without effects of diffusion. Then the interesting value of $x$ within the reaction layer is much smaller than $w$. On the other hand, $c_{+}$near the cathode is almost zero, leading to $\left(c_{+}\right)_{x \approx 0}<<$ $j w / F D$. Then Equation $\mathrm{S} 16$ for $x \approx 0$ becomes

$$
c_{-}=\frac{j}{F D}\left(\frac{w}{2}-x\right)+c_{+} \approx \frac{j w}{2 F D}
$$

and Equation S10 can be reduced to

$$
\frac{\mathrm{d}^{2} c_{+}}{\mathrm{d} x^{2}}=-\frac{k_{\mathrm{d}}\left[\mathrm{H}_{2} \mathrm{O}\right]}{D}+\frac{k_{\mathrm{r}} j w}{2 F D^{2}} c_{+}
$$

It is further written as

$$
\frac{\mathrm{d}^{2}\left(c_{+} / c^{*}\right)}{\mathrm{d} x^{2}}=\frac{k_{\mathrm{r}} j w}{2 F D^{2}}\left(\frac{c_{+}}{c^{*}}-\frac{2 k_{\mathrm{d}}\left[\mathrm{H}_{2} \mathrm{O}\right] F D}{c^{*} k_{\mathrm{r}} j w}\right)=\frac{\lambda^{2} g}{w^{2}}\left(\frac{c_{+}}{c^{*}}-\frac{2}{g}\right)
$$

where

$$
g=\frac{j w}{F c^{*} D}, \lambda=w \sqrt{\frac{k_{r} c^{*}}{2 D}}
$$

A solution of Equation S19 is given by

$$
\frac{c_{+}}{c^{*}}=\frac{2}{g}-B \exp \left(-\frac{\lambda}{w} \sqrt{g} x\right)
$$

where $B$ is a constant. Applying condition S14 to Equation S21 yields

$$
\frac{j}{F}=B D \frac{\lambda}{w} \sqrt{g}
$$

Subtracting $B$ from the above equation and Equation S21 for $x=0$, we have

$$
\frac{\left(c_{+}\right)_{x=0}}{c^{*}}=\frac{2}{g}-\frac{j w}{F c^{*} D \lambda \sqrt{g}}=\frac{2}{g}-\frac{\sqrt{g}}{\lambda}
$$

On the other hand, we assume that the reaction at the anode $\left(\mathrm{H}_{2} \rightarrow 2 \mathrm{H}^{+}+2 \mathrm{e}^{-}\right)$is in equilibrium, $\mathrm{H}^{+}+\mathrm{OH}^{-} \leftrightarrow \mathrm{H}_{2} \mathrm{O}$, because the produced amount of $\mathrm{H}^{+}$at the anode is smaller than the consumed amount of $\mathrm{H}^{+}$at the cathode. Then Equation $\mathrm{S} 16$ at $x=w$ is given by

$$
\left(c_{+}\right)_{x=w}=K_{\mathrm{w}} /\left(c_{+}\right)_{x=w}=j w / 2 F D
$$

or

$$
\left(c_{+}\right)_{x=w} / c^{*}=g / 4+\sqrt{g^{2} / 16+1}
$$

Subtracting the two Nernst equations S13 and replacing $\left(c_{+}\right)_{x=0}$ and $\left(c_{+}\right)_{x=w}$ by Equation S19 and S23, respectively, we have

$$
\frac{F \Delta E}{R T} \equiv \frac{F\left(E_{\mathrm{A}}-E_{\mathrm{C}}\right)}{R T}=\ln \frac{\left(c_{+}\right)_{x=w}}{\left(c_{+}\right)_{x=0}}=\ln \frac{\lambda g\left(g+\sqrt{g^{2}+16}\right)}{4\left(2 \lambda-g^{3 / 2}\right)}
$$

\section{Publish your work in this journal}

Reports in Electrochemistry is an international, peer-reviewed, open access journal publishing original research, reports, reviews and commentaries on all areas of electrochemistry. The manuscript management system is completely online and includes a very quick and fair

peer-review system. Visit http://www.dovepress.com/testimonials.php to read real quotes from published authors.

\section{Dovepress}

